\title{
Karyological Analysis of a Stingless Bee, Melipona favosa (Apidae, Hymenoptera) ${ }^{1}$
}

\author{
Hidehiro Hoshiba \\ Laboratory of Biology, Daito Bunka University, Dai-Ichi High School, \\ Takashima Daira, Itabashi-ku, Tokyo, 175 Japan
}

Accepted December 27, 1986

Among the genus Melipona, the chromosome number was observed in eleven species (Kerr 1948, 1952, 1972a, Kerr and Silveira 1972, Almeida 1981), all having $\mathrm{n}=9$ (in the male), except for $M$. quinquefasciata $(\mathrm{n}=18)$ as shown in Table 1 . The G-banding analysis of $M$. quadrifasciata anthidioides was proposed by Tambasco et al. (1979). But no detailed karyological study has been reported. The male meiosis of $M$. marginata was investigated by Kerr (1972b). It was assured that low temperature may cause the polyploidy. The diploid males were observed and cytologically analysed in $M$. quadrifasciata and the mechanism of the sex determination was discussed by Camargo (1979).

The present study deals with the karyological analysis of $M$. favosa of which chromosomes were not yet published.

\section{Materials and methods}

The colonies of $M$. favosa were brought from Surinum and have been kept in the laboratory of comparative physiology, University of Utrecht. The reproductive organs were taken from larvae and pupae. They were pretreated with a hypotonic solution $(0.4 \% \mathrm{KCl}$, $0.01 \%$ colchicin), and preparations were made according to the method described by Imai et al. (1977) with slight modification, and were stained by Giemsa solution. The measured values of the chromosomes were compared by t-test. Nomenclature of the chromosomes followed the system of Levan et al. (1964).

\section{Results and discussion}

The chromosome number of $M$. favosa was $\mathrm{n}=9$ in the male and they consist of 6 metacentric, 2 submetacentric, and one subtelocentric chromosomes. They were divided into two groups according to their length, i.e., A: nos. 1-3, larger group and B: nos. 4-9, smaller group (Fig. 1). The average length of the chromosomes from 15 reliable metaphase plates were determined (Table 2). The longest chromosome was $2.6 \mu \mathrm{m}$ and the shortest $1.8 \mu \mathrm{m}$. The significant difference was recognized by t-test between the groups $(p<0.05)$. The metaphase plate and the serial alignment according to the chromosome length are shown in Fig. 1. A secondary constriction can be observed in the long arm of the chromosome no. 1 . In females, $18(2 n)$ chromosomes were observed.

The G-banding of $M$. quadrifasciata anthidioides was analyzed by Tambasco et al. (1979), but information on the chromosome morphology (each chromosome type, arm ratio and relative length) was not proposed. However, it is estimated from the figure of Tambasco et al. (1979) that the chromosomes consist of 4 or 3 metacentric chromosomes, 4 or 5 sub-

${ }_{1}$ The present paper was partially supported by a grant from Daito Bunka University, in aid for scientific research, 1985. 
metacentric chromosomes and a telocentric chromosome. These results in M. quadrifasciata anthidioides do not agree with the results of the present study in $M$. favosa.

The phylogenical relationship between honey bees and stingless bees has been discussed. Stingless bees were considered
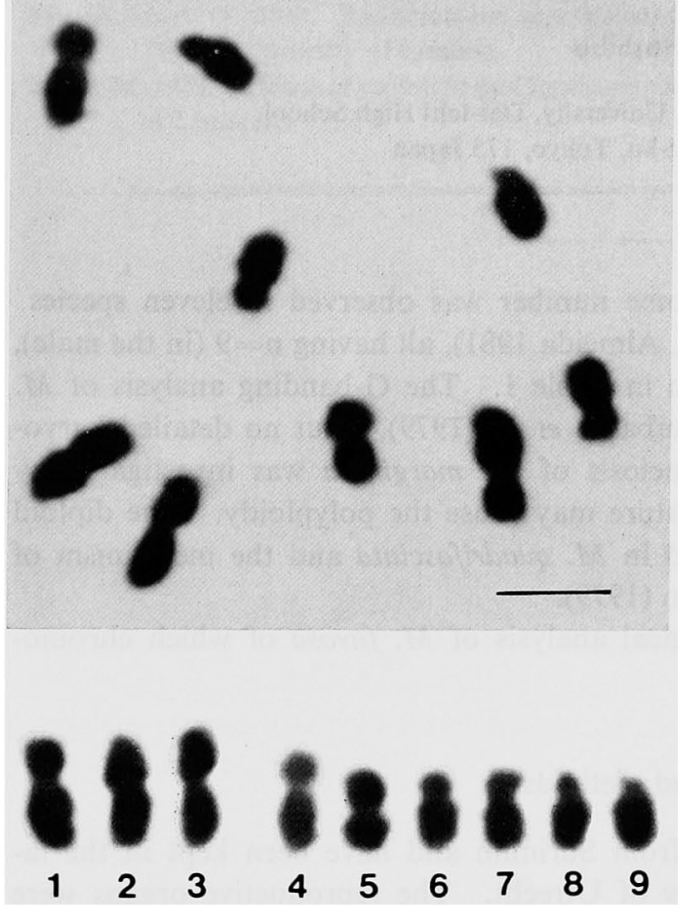

Fig. 1. Metaphase chromosomes of male $(n=9)$ Melipona favosa (above) and its karyotype pattern (bellow). Bar indicates $2.5 \mu \mathrm{m}$. the closest relative of honey bees. Nevertheless, thier unique behaviour seems to assure the independent achievement of eusocialty by stingless bees and honey bees (Sakagami 1982).

The chromosome number of stingless bees ranges from $\mathrm{n}=9$ (most of Melipona) to $n=17$ (most of Trigana) and $n=18$ ( $M$. quinquefasciata). The basic chromosome number for the genus Melipona may be $\mathbf{n}=$ 9 , as this number has been reported for most species, being smaller than in the honey bees.

In the honey bees, the chromosome numbers in all Apis are $\mathrm{n}=16$ (Farenhorst 1979). The karyological analyses have been worked out in A. mellifera and in A. cerana japonica by Hoshiba and Okada (1986). The karyotype patterns of these Apis species were very closed; 4 metacentric and 12 submetacentric or subtelocentric chromosomes (small but distinct differences were found between the chromosomes of these species).

The G-banding patterns on the chromosomes of $M$. quadricasciata anthidioides (Tambasco et al. 1979) are different from those of honey bees (Hoshiba and Okada 1986). Thus, chromosome common between Melipona and Apis which suggests a common ancestor seems not to be found in the present study.

Table 1. Chromosome number in Melipona

\begin{tabular}{llll}
\hline \hline \multicolumn{1}{c}{ Species } & Male & Female & \multicolumn{1}{c}{ References } \\
\hline M. quadrifasciata anthidioides & $\mathrm{n}=9$ & - & Kerr 1948 \\
M. marginata marginata & $\mathrm{n}=9$ & - & Kerr 1948 \\
M. schencki schencki & $\mathrm{n}=9$ & - & Kerr 1948 \\
M. fasciata & $\mathrm{n}=9$ & - & Kerr 1948 \\
M. rufivientris ruficientris & - & $2 \mathrm{n}=18$ & Kerr 1952 \\
M. nigra & $\mathrm{n}=9$ & $2 \mathrm{n}=18$ & Kerr 1952 \\
M. interrupta fasciculata & $\mathrm{n}=9$ & $2 \mathrm{n}=18$ & Kerr 1952 \\
M. subnitida & $\mathrm{n}=9$ & - & Kerr and Silveira 1972 \\
M. compressipes manaosensis & $\mathrm{n}=9$ & - & Kerr 1972 \\
M. quinquefasciata & $\mathrm{n}=18$ & - & Kerr 1972 \\
M. scutellaris & $\mathrm{n}=9$ & $2 \mathrm{n}=18$ & Almeida 1981 \\
M. favosa & $\mathrm{n}=9$ & $2 \mathrm{n}=18$ & Present study \\
\hline
\end{tabular}


Table 2. Karyotype characterstics of Melipona favosa

\begin{tabular}{ccccc}
\hline \hline No. & L. (SE) & R.L. & A.R. (SE) & Type \\
\hline 1 & $2.600(0.090)$ & 13.34 & $1.605(0.041)$ & M \\
2 & $2.584(0.074)$ & 13.26 & $1.059(0.009)$ & M \\
3 & $2.577(0.079)$ & 13.22 & $1.210(0.030)$ & M \\
4 & $2.271(0.099)$ & 11.65 & $1.530(0.055)$ & M \\
5 & $2.051(0.067)$ & 10.52 & $1.130(0.034)$ & M \\
6 & $1.909(0.068)$ & 9.79 & $1.817(0.077)$ & SM \\
7 & $1.908(0.048)$ & 9.79 & $1.507(0.064)$ & M \\
8 & $1.797(0.047)$ & 9.22 & $2.392(0.078)$ & SM \\
9 & $1.794(0.043)$ & 9.20 & $3.841(0.172)$ & ST \\
\hline
\end{tabular}

L.: length in $\mu \mathrm{m}$ with SE (standard errors).

R.L.: relative length expressed as \% of the total chromosome length.

A.R.: arm ratio with SE, length of long arm divided by that of short arm of the chromosome.

Type: M: metacentric chromosome (A.R. $=1.00-1.69$ ).

SM: submetacentric chromosome (A.R. $=1.70-2.99$ ).

ST: subtelocentric chromosome (A.R. $=3.00-6.99$ ).

\section{Summary}

The karyotype of a stingless bee, Melipona favosa was analysed. The number of chromosomes was $\mathbf{n}=9$, consisted of 6 metacentric, 2 submetacentric and one subtelocentric chromosomes.

The basic chromosome number of the genus Melipona seems to be $\mathrm{n}=9$. No chromosome common between the genus Melipona and Apis was morphologically found in the present study.

\section{Acknowledgements}

The author wishes to express his sincere appreciation to Prof. Dr. H. H. Velthuis and Dr. M. J. Sommeijer of University of Utrecht for preparing the materials.

He also thanks to Prof. Dr. S. F. Sakagami of Hokkaido University for his variable advices.

\section{References}

Almeida, M. G. de. 1981. Estudo sobre o numero de cromossomes e contagem de espermatozóides na abelha Melipona scurellaris, La reille, 1811. Ciência e Cultula 33(4): 539-542.

Camargo, C. A. de. 1979. Sex determination in bees XI. Production of diploid males and sex determination in Melipona quadrifasciata. J. Apic. Res. 18(2): 77-84.

Farenhorst, H. 1979. Nachweis über einstimmender Chromosomen-Zahlen $(\mathrm{n}=16)$ bei allen 4 Apis-Arten. Apidologie 8: 89-100.

Hoshiba, H. 1984. Karyotype and banding analyses on haploid males of the honey been (Apis mellifera). Proc. Japan Acad. 60B: 122-124.

- and Kusanagi, A. 1978. Karyological study of honeybee. J. Apic. Res. 17: 105-109.

- and Okada, I. 1986. G-banding analyses of male chromosomes in Apis cerana and A. mellifera ligustica. Apidologie. Apidologie 17(2): 101-106.

Imai, H. T., Crozier, R. H. and Taylor, R. W. 1977. Karyotype evolution in Australian ants. Chromosoma (Berl.) 59: 341-393.

Kerr, W. E. 1948. Estudos rôbre o Gênero Melipona. Anais Esc. Sup. Agric. Luiz Queiroz 6: 181-276.

- 1952. A variação do número de cromosomeas na ecolução dos Hymenoptera. Sientia Genet. 4(3): 282-190.

- 1972a. Numbers of chromosomes in some species of bees. J. Kans. Ent. Soc. 45: 111-122.

- 1972b. Effect of low temperature on male meiosis in Melipona marginata. J. Apic. Res. 11(2): 95-99.

- and Silveira, Z. V. da 1972. Karyotype evolution of bees and corresponding taxonomic implications. Evolution 26: 197-202. 
Levan, A., Fredga, K. and Sandberg, A. A. 1964. Nomenclature for centromeric position on chromosomes. Hereditas 52: 201-220.

Sakagami, S. F. 1982. Stingless bees. In: Hermann, H. R. (ed.), Social Insects. Vol. 3. Academic Press, N. Y. pp. 361-423.

Tambasco, A. J., Giannoni, M. A. and Moreira, L. M. de A. 1979. Analyses of G-bands in chromosomes of the Milipona quadrifasciata anthidiodes Lepeletier (Hymenoptera, Apidae, Meliponinae). Cytologia 44: 21-27. 